\title{
Hospital-based caesarean section in the Arab region: an overview
}

M. Khawaja, ${ }^{1}$ N. Choueiry ${ }^{1}$ and R. Jurdi ${ }^{1}$

$$
\text { العملية القيصرية في مستشفيات المنطقة العربية: نظرة عامة }
$$

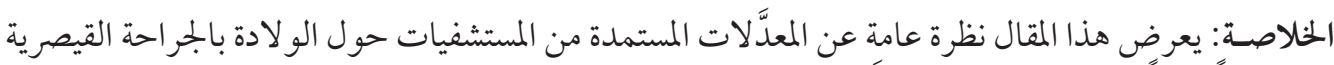

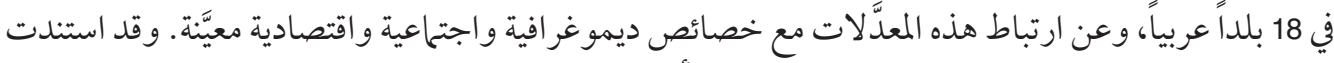

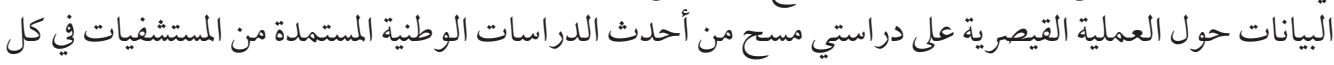

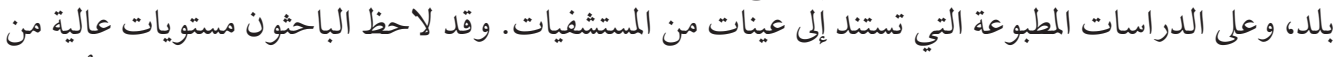

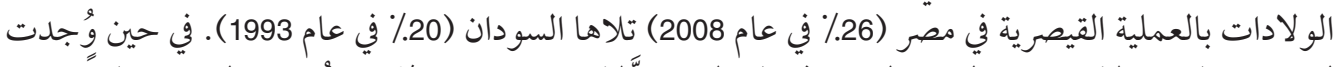

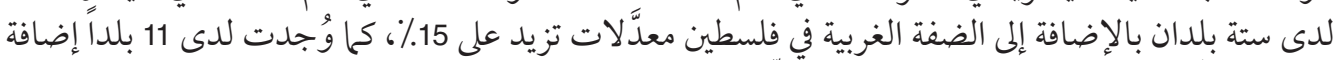

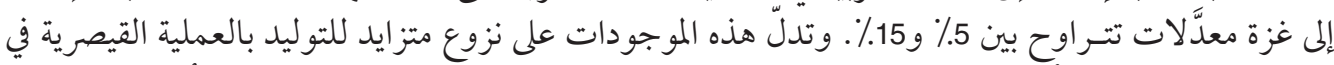

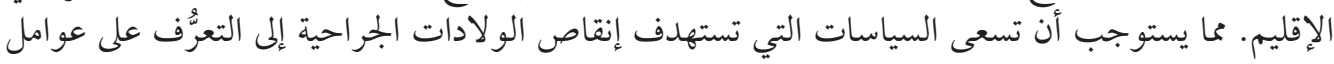
الاختطار هذه و التعاطي معها.

ABSTRACT This article provides an overview of hospital-based rates of caesarean delivery in 18 Arab countries and the association between these rates and selected demographic and socioeconomic characteristics. Data on caesarean section were based on 2 of the most recent national hospital-based surveys in each country and on published studies based on hospital samples. High levels of caesarean delivery were found in Egypt (26\% in 2003), followed by Sudan (20\% in 1993). Six countries and the West Bank area of Palestine had rates $>15 \%$ and 11 countries and Gaza had rates between $5 \%$ and $15 \%$. The findings indicate an increasing trend of caesarean section delivery in the region. Policies aiming at reducing surgical deliveries should seek to identify and address these risk factors.

\section{La césarienne en milieu hospitalier dans la région arabe : situation générale}

RÉSUMÉ Cet article présente un aperçu des taux d'accouchement par césarienne dans les hôpitaux de 18 pays arabes, et l'association entre ces taux et certaines caractéristiques démographiques et socioéconomiques. II s'appuie sur des données relatives à la césarienne provenant de deux des enquêtes nationales les plus récentes menées en milieu hospitalier dans chaque pays et sur des études publiées portant sur des échantillons hospitaliers. Des niveaux élevés d'accouchement par césarienne ont été observés en Égypte (26\% en 2003), ainsi qu'au Soudan (20\% en 1993). Six pays et le territoire palestinien de Cisjordanie avaient des taux supérieurs à $15 \%$ et 11 pays et Gaza, des taux compris entre $5 \%$ et $15 \%$. Les données recueillies montrent une tendance à la hausse des accouchements par césarienne dans la région. Les politiques visant à réduire les accouchements chirurgicaux devraient s'efforcer de recenser les facteurs de risque et de s'y attaquer.

${ }^{1}$ Center for Research on Population and Health, Faculty of Health Sciences, American University of Beirut, Beirut, Lebanon (Correspondence to M. Khawaja: mk36@aub.edu.Ib).

Received: 01/05/06; accepted: 05/09/06 


\section{Introduction}

During the past few decades, the caesarean section (CS) delivery rate has been increasing almost everywhere, and the Arab region is no exception. Although the actual risk of death from CS is decreasing in the western world, data extrapolated from confidential enquiries in the United Kingdom estimated the risk of maternal death from CS is still 3 times greater than that with vaginal delivery [1]. Previous studies also indicate greater levels of morbidity and infertility among women undergoing CS [2].

The countries of the Arab world show a large discrepancy in their population-based CS rates, with some countries having exceptionally high CS rates and others very low rates. Such differences can be accounted for largely by each country's level of development [3]. Although rates exceeding 15\% are unnecessarily high, very low rates are also problematic as they may reflect lack of access to needed obstetric care in some low-income countries. Thus, policies to reduce or increase $\mathrm{CS}$ deliveries have been suggested, depending on the context in question.

Information on rates of CS is not easily obtained for most Arab countries because of the lack of good national registration systems. Prevalence estimates of hospitalbased CS in 18 Arab countries are available from reports based on nationally representative surveys and small-scale facility-based studies. The purpose of this paper is to review the available evidence and describe levels and trends of CS delivery in countries for which data are available. Specifically, the paper aims to document and examine the most recent estimates of CS delivery across countries, and describe countryspecific trends. In addition, the paper intends to examine within-country variations in CS delivery by selected socioeconomic characteristics of respondents.

\section{Methods}

For this review, we relied on hospitalbased estimates of CS as these capture more accurately the prevalence of this procedure. The national-level estimates are largely drawn from reports of the Pan Arab Project for Child Development (PAPCHILD) of the League of Arab States and United Nations Population Fund (UNFPA), the Gulf Family Health Survey (FHS) and the Demographic and Health Survey (DHS) programmes. These surveys used similar data collection and estimation methods, with the national surveys based on standardized instruments and representative samples, thus enhancing comparability of estimates between countries and over time. Neither PAPCHILD nor DHS provided data for the Occupied Palestinian Territories. We therefore relied on data from the Palestinian Central Bureau of Statistics, an annual published report on the health status of Palestinians published by the Palestinian Ministry of Health. All these national surveys provided information on aspects of pregnancy and childbirth, as well as on issues relating to antenatal and postnatal care. Specifically, mothers were asked if they had any pregnancy during the 5 years preceding the survey, and about complications during delivery, if any.

Our review of available survey-based evidence proceeded as follows. First, microdata from the DHS programme were used for Egypt, Yemen and Mauritania [4]. For Jordan, we used data from the published DHS report [4]. For the Palestinian Territories, the 1996 Health Survey in the West Bank and Gaza Strip, designed and implemented by the Palestinian Central 
Bureau of Statistics, was used to calculate estimates for the Palestinian areas [5]. The Palestinian analysis is split by region because of the large differences between the West Bank and the Gaza Strip. Finally, data for the remaining countries were obtained from published reports of national surveys carried out by PAPCHILD. Published reports from the Arab Maternal and Child Health Survey programme were used for Algeria, Lebanon, Libyan Arab Jamahiriya, Morocco, Sudan and Tunisia, countries where national microdata could not be accessed [6-11]. Likewise, the Gulf Family Health Survey reports were used for information about Bahrain, Kuwait, Oman, Qatar, Saudi Arabia and the United Arab Emirates [12-17].

In addition, published studies were reviewed for recent hospital-based estimates from data collected in facilities. A Medline/ PubMed search was made for all studies on CS done between 1980 and 2005 in hospitals of any country in the Arab region. The following terms were used for this purpose: "caesarean section + Arab", "caesarean + trends", and "caesarean section + statistics and numerical data". Eligible studies included those with hospital-based samples. We excluded studies reporting estimates based on interventions or high-risk populations such as breech births and diabetic patients.

For the analysis, we first estimated or documented hospital CS rates for the countries under examination. For all national estimates reported here, confidence intervals were calculated to assess the significance of the differences in the estimated rates. Bivariate analyses with selected socioeconomic indicators were undertaken to better understand the differentials in CS rates for selected countries in the Arab region. We confined this analysis to mother's age, education and place of residence owing to the availability of data, particularly in countries where microdata could not be accessed.

\section{Results}

Figure 1 summarizes the most recent hospital-based CS rates based on nationallevel household surveys. There was a large variation in the CS rates found across countries, with Egypt having the highest CS rate at $26.2 \%$ and Mauritania the lowest at $5.3 \%$. Six countries (Egypt, Sudan, Jordan, Lebanon, Bahrain and Qatar) had CS rates exceeding the World Health Organization (WHO) threshold of $15 \%$, with the remaining 13 countries having CS rates between $5 \%$ and $15 \%$. Syrian Arab Republic, Kuwait and Tunisia had CS rates between $10 \%$ and 15\%. Libyan Arab Jamahiriya, Morocco, Oman, Saudi Arabia, United Arab Emirates and West Bank had CS rates between 7\% and 9\%. Finally, Algeria, Mauritania, Gaza and Yemen had the lowest rates at 5\%-6\%.

Rates of CS from 17 hospital-based studies were available for Jordan, Kuwait, Lebanon, Saudi Arabia and United Arab Emirates (Table 1); 9 of these studies were conducted in Saudi Arabia and 5 in Jordan. Most of these studies (9 of 12) were based on samples from a single hospital. Results from the hospital-based studies were often different from those produced by national household surveys. In Jordan, a study estimated a CS rate of $7.7 \%$ during the period 1991-97 [18], compared to a rate of almost $13 \%$ in the 1997 Jordan Demographic Health Survey [4]. However, a hospital-based study conducted in 1990-92 produced a very similar rate, $8.0 \%$ [19], as did the 1990 Jordan Demographic Health Survey, estimated at $8.5 \%$ [4]. In the case of Saudi Arabia, a study reported a CS rate ranging between $12 \%$ and $13 \%$ for the years 1996-97 based on a different facility 


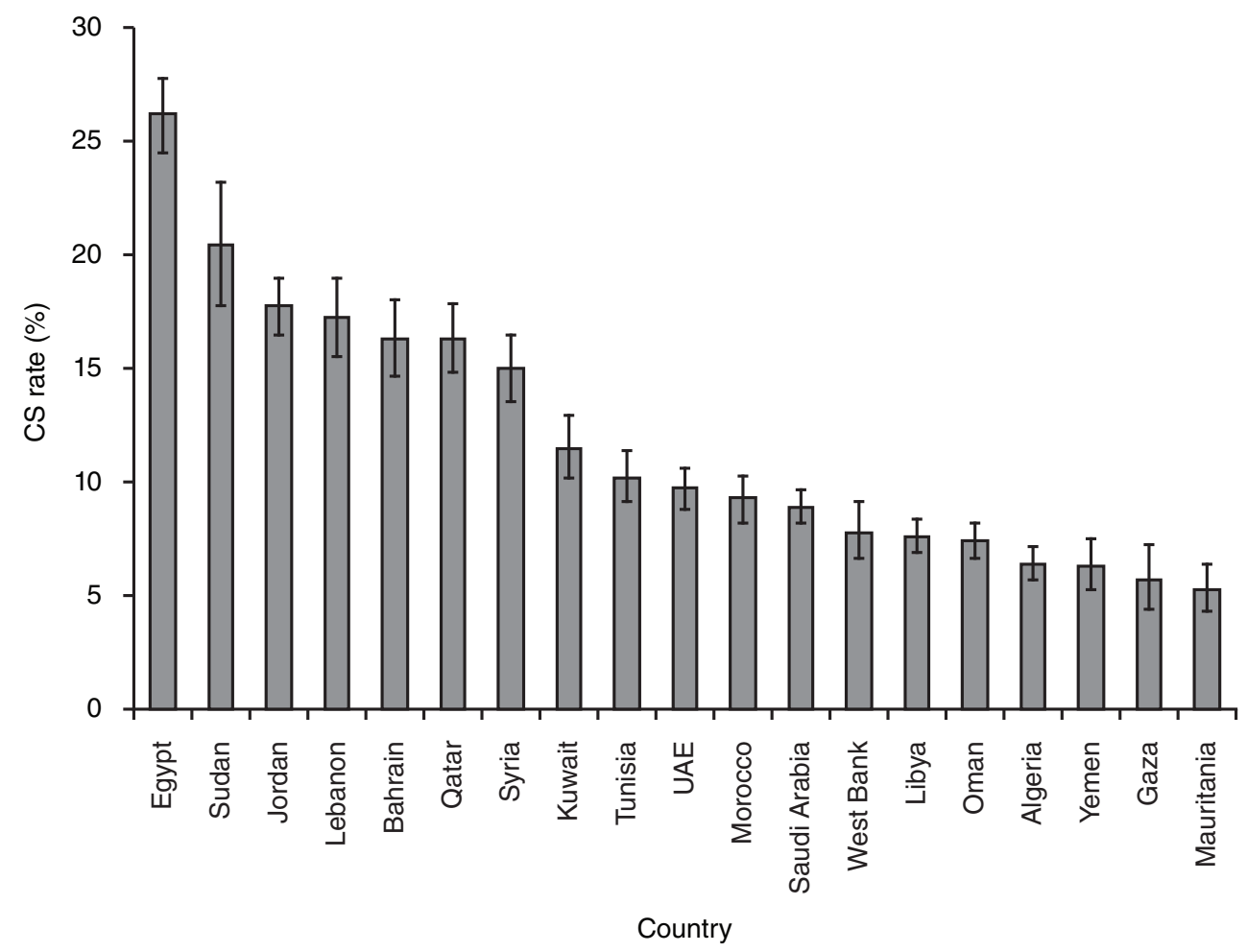

Figure 1 Hospital-based caesarean section (CS) rates and confidence intervals in selected Arab countries

[20], but for the 1992-96 period, another study documented a CS prevalence rate of around $9.5 \%$ [21]. Two other studies implemented in 2 different hospitals during 1994 calculated slightly different CS rates, 9.9\% and $11.5 \%[22,23]$. All the hospital-based studies, including 1 conducted in 1984, reported rates higher than the estimate of 8.9\% published by the 1996 Saudi Arabia Family Health Survey [16]. In United Arab Emirates, a hospital-based study showed a CS rate of $6.9 \%$ in 1994 [24], which was lower than the national survey estimate of $9.7 \%$ in 1995 [17]. The hospital-based studies in Kuwait and Lebanon showed CS rates slightly different from the national survey estimates $[7,13,25,26]$. However, these rates are not strictly comparable because they were conducted in different time periods.

There has been a trend of rising CS delivery rates across countries in the region (Table 1). The CS rate in Jordan increased from $7.7 \%$ in 1991 to $17.8 \%$ in 2002 . In Egypt, there was also a sharp increase in the CS rate from a $15.3 \%$ in 1992 to $26.2 \%$ in 2003. During the period between 1992 and 2003-04, Moroccan CS rates showed a slower increase from $6.8 \%$ to $9.3 \%$. Within almost the same time period, the CS rates in the Syrian Arab Republic increased from $12 \%$ in 1993 to $15 \%$ in 2002 . Similarly, 


\begin{tabular}{|c|c|c|c|c|c|}
\hline Country & CS rate (\%) & Year & Survey & Scope & $\begin{array}{c}\text { Source } \\
\text { [reference] } \\
\text { (year) }\end{array}$ \\
\hline Algeria & 6.4 & 1993 & AMCHS & National & [6] (1994) \\
\hline Bahrain & 16.3 & 1995 & BFHS & National & [12] (1995) \\
\hline \multirow[t]{6}{*}{ Egypt } & 26.2 & 2003 & EDHS & National & [4] (2003) \\
\hline & 20.9 & 2000 & EDHS & National & [4] (2000) \\
\hline & 22.0 & 1999-2000 & & National & [27] \\
\hline & 18.5 & 1995 & EDHS & National & [4] (1995) \\
\hline & 15.3 & 1992 & EDHS & National & [4] (1992) \\
\hline & 13.9 & 1987-1988 & & National & [27] \\
\hline \multirow[t]{8}{*}{ Jordan } & 17.8 & 2002 & JDHS & National & [4] (2002) \\
\hline & 10.9 & 1999-2001 & & 7 hospitals & [19] \\
\hline & 12.9 & 1997 & JDHS & National & [4] (1997) \\
\hline & 8.8 & 1995 & & 1 hospital & [28] \\
\hline & 8.5 & 1990 & JDHS & National & [4] (1990) \\
\hline & 8.0 & 1990-1992 & & 7 hospitals & [19] \\
\hline & 7.7 & 1991-97 & & 1 hospital & [18] \\
\hline & $8.7-15.5$ & 1987-1993 & & 1 hospital & [29] \\
\hline \multirow[t]{2}{*}{ Kuwait } & 11.5 & 1996 & KFHS & National & [13] (1996) \\
\hline & 9.4 & $1983-88$ & & 4 hospitals & [25] \\
\hline \multirow[t]{2}{*}{ Lebanon } & 18.0 & 2000 & & $\begin{array}{c}\text { National } \\
\text { randomized } \\
\text { sample of } 39 \\
\text { hospitals }\end{array}$ & [26] \\
\hline & 17.2 & 1995-96 & LMCHS & National & [7] (1996) \\
\hline \multicolumn{6}{|l|}{ Libyan Arab } \\
\hline Jamahiriya & 7.6 & 1995 & ALMCHS & National & [8] (1996) \\
\hline \multirow[t]{2}{*}{ Mauritania } & 6.6 & $2000-1$ & MDHS & National & [4] (2001) \\
\hline & 5.2 & $1990-1$ & MMCHS & National & [30] (1992) \\
\hline \multirow[t]{4}{*}{ Morocco } & 9.3 & 2003-2004 & MDHS & National & [4] (2004) \\
\hline & 15.3 & 1999 & MMCHS & National & [9] \\
\hline & 8.0 & 1995 & MDHS & National & [4] (1995) \\
\hline & 6.8 & 1992 & MDHS & National & [4] (1992) \\
\hline Oman & 7.4 & 1995 & OFHS & National & [14] (1995) \\
\hline Palestine & 7.0 & 1996 & PHS & & [5] (1997) \\
\hline \multirow[t]{2}{*}{ West Bank } & 15.7 & 2003 & $\mathrm{MOH}-\mathrm{PHIC}$ & $\mathrm{MOH}$ hospitals & [31] (2004) \\
\hline & 7.8 & 1996 & PDS & National & [5] (1997) \\
\hline \multirow[t]{2}{*}{ Gaza } & 14.4 & 2003 & $\mathrm{MOH}-\mathrm{PHIC}$ & $\mathrm{MOH}$ hospitals & [31] (2004) \\
\hline & 5.7 & 1996 & PDS & National & [5] (1997) \\
\hline $\begin{array}{l}\text { Qatar } \\
-\end{array}$ & $\begin{array}{c}16.3 \\
--\end{array}$ & 1998 & QFHS & National & [15] (1998) \\
\hline
\end{tabular}


Table 1 Published hospital-based caesarean section (CS) rate in selected Arab countries (concluded)

\begin{tabular}{lccccc}
\hline Country & CS rate (\%) & Year & Survey & Scope & $\begin{array}{c}\text { Source } \\
\text { [reference }] \\
\text { (year) }\end{array}$ \\
\hline Saudi & 13.0 & 2002 & & 6 PHCs & {$[32]$} \\
Arabia & $19.4^{\mathrm{a} ;}, 18.3^{\mathrm{b}}$ & $1997-99$ & & 1 hospital & {$[33]$} \\
& $12.0-13.0$ & $1996-97$ & & 1 hospital & {$[20]$} \\
& 8.9 & 1996 & SAFHS & National & {$[16](1996)$} \\
& 9.9 & 1994 & & 1 hospital & {$[22]$} \\
& $11.5-13.4$ & $1994-99$ & & 1 hospital & {$[23]$} \\
& 9.5 & $1992-96$ & & 1 hospital & {$[21]$} \\
Sudan & 10.3 & $1989-93$ & & 1 hospital & {$[34]$} \\
Syrian Arab & 9.9 & 1984 & & 1 hospital & {$[35]$} \\
Republic & 15.0 & 1993 & SMCHS & National & {$[10](1995)$} \\
Tunisia & 12.0 & 2002 & SFHS & National & {$[36](2002)$} \\
United Arab & 10.2 & 1993 & SMCHS & National & {$[37](1995)$} \\
Emirates & $9.3^{\mathrm{c}} ; 15.2^{\mathrm{d}}$ & $1994-95$ & TMCHS & National & {$[11](1996)$} \\
& 9.7 & $1996-8$ & & 1 hospital & {$[38]$} \\
Yemen & 6.9 & 1995 & EFHS & National & {$[17](1995)$} \\
& 6.3 & 1994 & & National & {$[24]$} \\
& 11.2 & 1997 & YDHS & National & {$[4](1997)$} \\
\hline
\end{tabular}

${ }^{a}$ Nulliparous women; ${ }^{b}$ grand multiparous women; ${ }^{c}$ non-obese women; ${ }^{d}$ obese women.

$\mathrm{MOH}=$ Ministry of Health; $\mathrm{PHCs}=$ primary health centres.

CS rates increased in Saudi Arabia from $9.9 \%$ in 1984 to $13.0 \%$ in 2002 . Finally, in Lebanon the CS rate increased slightly from $17.2 \%$ in 1995 to $18.0 \%$ in 2000 .

Table 2 reports the associations between CS deliveries and selected background characteristics of respondents. Positive associations were found between CS rates and mother's age, education and place of residence. Overall, older women had higher rates of CS than younger women. Interestingly, the disparity in CS rates between older and younger women exceeded 5\% in 6 settings: Egypt, Kuwait, Lebanon, Qatar, Syrian Arab Republic, West Bank and Bahrain. In Kuwait, for example, the CS rate among women aged 35 years and above was $17.3 \%$ compared to only $4.8 \%$ among women aged 15-35 years. Smaller percentage differences, $7 \%-8 \%$, between the 2 age groups were observed for Egypt, Lebanon, Qatar, Syrian Arab Republic and West Bank. However, 3 countries (Algeria, Sudan and United Arab Emirates) had CS rates higher at younger ages than older ages. In Sudan, $25.2 \%$ of the women aged $15-34$ years had a CS whereas $14.8 \%$ of those aged $35+$ years had this surgical procedure.

In general highly educated women were more likely to undergo this surgery than their less educated counterparts (Table 2). The discrepancies were not that large, with the highest ranging between $5 \%$ and $6 \%$ in 5 out of the 17 countries. In Lebanon, for example, the CS rate among the less educated (below secondary school level) was $14.9 \%$ as compared to $20.1 \%$ among the more educated women. Egypt had a similar 
Table 2 Hospital-based caesarean section rates by age, education and residence in selected Arab countries

\begin{tabular}{lcccccc}
\hline Country & \multicolumn{2}{c}{ Mother's age (years) } & \multicolumn{2}{c}{ Mother's education } & \multicolumn{2}{c}{ Residence } \\
& $\mathbf{1 5 - 3 4}$ & $\mathbf{3 5 +}$ & $\begin{array}{c}\text { Below } \\
\text { secondary }\end{array}$ & $\begin{array}{c}\text { Secondary } \\
\text { or higher }\end{array}$ & Rural & Urban \\
& $\%$ & $\%$ & $\%$ & $\%$ & $\%$ & $\%$ \\
\hline Algeria & 6.8 & 6.1 & 6.7 & 10.0 & 5.7 & 6.9 \\
Bahrain & 15.2 & 17.8 & 17.0 & 17.9 & - & - \\
Egypt & 20.1 & 28.0 & 18.0 & 23.6 & 17.4 & 23.7 \\
Jordan & 5.8 & 10.7 & 7.0 & 6.6 & 5.2 & 7.3 \\
Kuwait & 4.8 & 17.3 & 9.9 & 12.1 & - & - \\
Lebanon & 14.5 & 21.2 & 14.9 & 20.1 & - & - \\
Mauritania & - & - & 2.4 & 9.4 & 0.5 & 4.2 \\
Morocco & 7.0 & 10.6 & 6.4 & 12.0 & 5.7 & 9.2 \\
Oman & 6.2 & 7.9 & 6.1 & 11.5 & 4.9 & 7.7 \\
Palestine Gaza & 4.2 & 9.6 & 5.2 & 6.2 & 4.7 & 6.6 \\
Palestine West Bank & 5.9 & 14.1 & 8.2 & 6.5 & 6.8 & 8.5 \\
Qatar & 13.9 & 21.4 & 14.7 & 16.5 & - & - \\
Saudi Arabia & 5.8 & 11.0 & 8.1 & 10.5 & 5.2 & 9.4 \\
Sudan & 25.2 & 14.8 & 18.9 & 22.9 & 24.4 & 18.6 \\
Syrian Arab Republic & 10.3 & 17.6 & 11.9 & 15.4 & 11.7 & 12.8 \\
United Arab & & & & & & \\
Emirates & 12.5 & 11.9 & 9.7 & 10.7 & 8.0 & 10.5 \\
Yemen & 6.0 & 7.7 & 6.4 & 3.0 & 6.3 & 6.2 \\
\hline
\end{tabular}

percentage difference, but at higher rates for both groups (18.0\% versus $23.6 \%)$. On the other hand, Jordan, West Bank and Yemen showed the opposite pattern, with rates of CS being relatively higher among less educated women than the more educated. However, the educational differentials in the CS rates in these 3 countries were rather small, with Yemen having the largest percentage difference of $3.4 \%$.

Likewise, the discrepancies in CS rates by rural and urban residence were relatively small, with no country exceeding 5\%. The highest rural-urban differentials in CS rates were in Egypt, Saudi Arabia and Sudan, amounting to $4 \%-5 \%$ differences. CS rates were higher among women living in urban areas than rural areas in all the countries, except Sudan and Yemen.

\section{Discussion}

This brief review revealed great disparities in the hospital-based CS rates across and within countries in the Arab region. The discrepancies may reflect differential accessibility to maternal health services where the rates are low, or to the misuse of medical technology in performing this surgical procedure in countries where the rates of CS at the hospital level are high. Results from facility-based studies were not always consistent with nationally-based surveys, perhaps due to the selectivity of the hospitals used in the small-scale studies. Trends in CS rates in countries where data were available at the national level for more than one time period generally showed increased use of this procedure, and a doubling within 
a decade in countries such as Egypt and Jordan. Such increases in the CS rates were not accompanied by consistent declines in the maternal mortality ratios during the past few decades. This may reflect the fact that women undergoing CS are not necessarily the ones who need them most.

Geographically, the disparities in the CS rate were evident within and across the 3 geographic regions of North Africa, Levant and the Gulf. Particularly high discrepancies were found among North African countries, with low rates in Algeria and Mauritania and high rates in Sudan and Egypt. The majority of the Gulf countries had CS rates below 15\%, except for Bahrain and Qatar, with rates of about $16 \%$ each. As for the Levant countries, the CS rates ranged from $14 \%$ in Gaza to $18 \%$ in Lebanon.

Thus, the reported rates did not seem to correspond with the countries' levels of socioeconomic development [3]. Egypt showed higher rates of CS than several other Arab countries with better socioeconomic profiles such as Bahrain, Qatar and United Arab Emirates [3]. Similarly, middle-income countries such as Jordan, Lebanon and Syrian Arab Republic had CS rates close to high-income counties such as Qatar or Bahrain [3].

Within countries, CS rates varied with nonmedical risk factors such as age, education and rural-urban residence. Specifically, women with secondary level of education, living in urban places and over 35 years of age were more likely to undergo CS deliveries than other women. The largest discrepancies in the CS rates were found by age. The positive association between CS delivery and maternal age is supported by other studies [39-42], and might be attributed to higher risks of complications as the age of the mother increases. Various studies found higher rates of labour fetal distress and failure to advance at the time of delivery among older mothers, all factors highly associated with CS delivery [40,43]. However, higher rates of CS among older women cannot entirely be explained by their tendency towards more complicated pregnancies and births [41]. In some situations, maternal preferences, perceived potential for complications by medical doctors, as well as convenience of delivery may also be important determinants of CS delivery [41].

However, in a few settings where teenage pregnancies were common, the CS rates were higher at younger ages. The case of Sudan is particularly alarming, with a difference in CS of more than $10 \%$ between younger and older women. We cannot determine the precise reasons for this finding with the data at hand, but the observed rates could be due to the relatively high rate of teenage pregnancies in this country.

Urban residents generally reported higher rates of CS than their rural counterparts. This finding is expected given the urban advantage in accessibility to better health care services and availability of skilled birth attendants, making it possible to detect complications that may require caesarean delivery $[40,42,44]$.

With a few exceptions, our findings show that women with secondary education had higher rates of CS than women with lower education. These findings are consistent with previous studies, and may reflect the tendency of educated women to seek care in health institutions [40]. A study in northern Thailand found that Thai women with social resources had more control over the experience of childbirth than other women [45]. It is doubtful if women in the Arab context have much choice over their mode of deliveries [26,46,47], with the observed disparities reflecting perhaps differential access to health care. 
This review has several limitations. First, the review relied mainly on published reports and aggregated data because the necessary microdata from the PAPCHILD and similar surveys in the region were not available to researchers (except the Arab League and UNFPA staff), despite the large costs in fielding such surveys. Secondly, national level data were available for only 1 year for most countries in the region. Thirdly, although reports from the majority of available surveys contained results for common risk factors, indicators of medical complications were rarely available. Fourthly, the questions concerning CS delivery in national level surveys such as the DHS or PAPCHILD have never been validated, and our review therefore excluded items concerning medical indications of CS delivery. Fifthly, although CS rates reported by nationally representative sample surveys may reflect true rates in the population, it was not possible to assess the bias and/or accuracy of facility-based studies. Finally, our review was confined to English language studies, thus excluding regional studies and findings written in Arabic or French.

\section{Conclusions}

This review shows large discrepancies in the CS rates but with an overall increasing trend in CS delivery. High rates of CS deliveries in low- and middle-income countries-exceeding the 15\% WHO thresh- old [48] - is of policy concern because of the medical effects and the high costs of undergoing operative deliveries. There is therefore a need to address the factors that increase the risk of operative deliveries in this part of the world in order to reduce the practice. Here, the emphasis should perhaps be placed on prevention involving individual behavioural aspects, with regard to decision-making of both the physician and the woman [40]. On the other hand, very low rates below the minimum 5\% specified by WHO, were observed for some vulnerable, or otherwise disadvantaged, groups of women in various countries. Here, increasing access to adequate health care facilities for rural, less educated and younger women should be emphasized.

Clearly, more in-depth research is needed in order to identify the individual risk factors involved in high CS rates, perhaps with an interdisciplinary approach encompassing social science and medical fields to better identify the challenges facing both the women and medical professionals in controlling this practice [49]. In addition, there are many country-specific factors that need to be taken into account in interpreting the data observed. Future studies should consider the importance of country-specific factors such as access to health care, careseeking behaviour, availability of staff and infrastructure, medical technology and the quality and continuity of care.

\section{References}

1. Hall HM, Bewley S. Maternal mortality and mode of delivery. Lancet, 1999, 354:776.

2. Gass CW. It is the right of every anaesthetist to refuse to participate in a maternal-request caesarean section? International journal of obstetric anesthesia, 2006, 15:33-5.
3. Jurdi R, Khawaja M. Caesarean section rates in the Arab region: a cross-national study. Health policy and planning, 2004, 19:101-10.

4. Demographic and health surveys. MEASURE DHS [website] (http://www.measuredhs.com, accessed 17 April 2008). 
5. Health survey in the West Bank and Gaza Strip-1996. Main findings. Ramallah, Palestine, Palestinian Central Bureau of Statistics, 1997.

6. Algeria Maternal and Child Health survey: principal report, 1994. Algiers, Algeria, Ministry of Health and Population, and the Pan Arab Project for Child Development of the League of Arab States.

7. Lebanon Maternal and Child Health Survey: principal report, 1998. Beirut, Lebanon, Ministry of Public Health, and Pan Arab Project for Child Development of the League of Arab States, 1998.

8. Arab Libyan Maternal and Child Health Survey: principal report, 1996. Tripoli, Libyan Arab Jamahiriya, General People's Committee for Health and Social Insurance, 1996.

9. Moroccan Maternal and Child Health Survey: principal report 2000. Rabat, Morocco, Ministry of Health, and Pan Arab Project for Child Development of the League of Arab States, 2000.

10. Sudan Maternal and Child Health Survey: principal report, 1995. Khartoum, Sudan, Ministry of Public Health, and Pan Arab Project for Child Development of the League of Arab States.

11. Tunisia Maternal and Child Health Survey: summary report 1996. Tunis, Tunisia, Ministry of Public Health, and Pan Arab Project for Child Development of the League of Arab States.

12. Naseeb T, Farid SM. Bahrain Family Health Survey 2000. Riyadh, Saudi Arabia, Gulf Family Health Survey, 2000.

13. Alnesef $Y$, Al-Rashoud R, Farid SM. Kuwait Family Health Survey. Riyadh, Saudi Arabia, Gulf Family Health Survey, 2000.

14. Sulaiman AJ, Al-Riyami A, Farid SM. Oman Family Health Survey. Riyadh, Saudi Arabia, Gulf Family Health Survey, 2000.
15. Al-Jaber KA, Farid SM. Qatar Family Health Survey. Riyadh, Saudi Arabia, Gulf Family Health Survey, 2000.

16. Khoja TA, Farid SM. Saudi Arabia Family Health Survey. Riyadh: Gulf Family Health Survey, 2000.

17. Fikri M, Farid SM. United Arab Emirates Family Health Survey. Riyadh, Saudi Arabia, Gulf Family Health Survey, 2000.

18. Akasheh HF, Amarin V. Caesarean sections at Queen Alia Military Hospital, Jordan: a six-year review. Eastern Mediterranean health journal, 2000, 6:41-5.

19. Hindawi IM, Meri ZB. The Jordanian cesarean section rate. Saudi medical journal, 2004, 25:1631-5.

20. Mesleh RA, Asiri F, Al-Naim M. Caesarean section in the primigravid. Saudi medical journal, 2000, 21:957-9.

21. Onuora VC et al. Major injuries to the urinary tract in association with childbirth. East African medical journal, 1997, 74(8):523-6.

22. Elhag BI, Milaat WA, Taylouni ER. An audit of caesarean section among Saudi females in Jeddah, Saudi Arabia. Journal of the Egyptian Public Health Association, 1994, 69:1-17.

23. Mesleh RA, Al Naim M, Krimly A. Pregnancy outcomes of patients with previous four or more caesarean sections. Journal of obstetrics and gynecology, 2001, 21: 355-7.

24. Hughes PF, Morrison J. Pregnancy outcome data in a UAE population: what can they tell us? Asia Oceania journal of obstetrics and gynecology, 1994, 20:18390.

25. Guirguis W, Al-Saleh K. Caesarean section in Kuwait, 1983 through 1988. Journal of the Egyptian Public Health Association, 1991, 66:451-75. 
26. Khayat R, Campbell O. Hospital practices in maternity wards in Lebanon. Health policy and planning, 2000, 15:270-8.

27. Khawaja M, Jurdi R, Kabakian-Kasholian $\mathrm{T}$. Rising trends in cesarean section rates in Egypt. Birth, 2004, 31:12-6.

28. Abu-Heija AT, Jallad MF, Abukteish F. Obstetrics and perinatal outcome of pregnancies after the age of 45 . Journal of obstetrics and gynecology, 1999, 19:486-8.

29. Ziadeh SM, Sunna El. Decreased cesarean birth rates and improved perinatal outcome: a seven-year study. Birth, 1995, 22:144-7.

30. Mauritania Maternal and Child Health Survey: principal report 1992. Nouakchott, Mauritania, National Statistical Office, and Pan Arab Project for Child Development of the League of Arab States, 1992.

31. Health status in Palestine 2003: hospitals, annual report. Ramallah, Palestine, Ministry of Health, Palestinian Health Information Center, 2004.

32. Shawky S, Abalkhail BA. Maternal factors associated with the duration of breast feeding in Jeddah, Saudi Arabia. Paediatric and perinatal epidemiology, 2003, 17:91-6.

33. Sobande AA, Archibong El, Eskandar M. Primary caesarean section in nulliparous and grandmultiparous Saudi women from the Abha region: indications and outcomes. West African journal of medicine, 2003, 22:232-5.

34. Soltan $\mathrm{MH}$, Khashoggi $\mathrm{T}$, Adelusi B. Pregnancy following rupture of the pregnant uterus. International journal of gynaecology and obstetrics, 1996, 52:37-42.

35. Chattopadhyay SK et al. Cesarean section; changing patterns in Saudi Arabia. International journal of gynecology and obstetrics, 1987, 25:387-94.
36. Family Health Survey in the Syrian Arab Republic: summary report 2002. Damascus, Syrian Arab Republic, Central Bureau of Statistics, and Pan Arab Project for Family Health of the League of Arab Sates.

37. Syrian Maternal and Child Health Survey: principal report 1992. Damascus, Syrian Arab Republic, Central Bureau of Statistics, and Pan Arab Project for Child Development of the League of Arab States.

38. Kumari AS. Pregnancy outcome in women with morbid obesity. International journal of obstetrics and gynecology, 2001, 73:101-7.

39. Khawaja M, Kabakian-Kasholian T, Jurdi R. Determinants of caesarean section in Egypt: evidence from the demographic and health survey. Health policy, 2004 , 69:273-81.

40. Padmadas SS et al. Caesarean section delivery in Kerala, India: evidence from a National Family Health Survey. Social science and medicine, 2000, 51:511-21.

41. Bell JS et al. Do obstetric complications explain high caesarean section rates among women over 30 ? A retrospective analysis. British medical journal, 2001, 322:894-5.

42. Webster LA et al. Prevalence and determinants of caesarean section in Jamaica. Journal of biosocial science, 1992 , 24(4):515-25.

43. Rosenthal AN, Paterson-Brown S. Is there an incremental rise in the risk of obstetric intervention with increasing maternal age? British journal of obstetrics and gynaecology, 1998, 105:1064-9.

44. Ondimu KN. Levels and risk factors of operative deliveries in four health facilities in Kisumu District, Kenya. Journal of obstetrics and gynecology, 2000, 20(5):486-91.

45. Liamputtong $P$. Birth and social class: Northern Thai women's lived experiences 
of caesarean and vaginal birth. Sociology of health and illness, 2005, 27:243-70.

46. Bashour H, Abdulsalam A. Syrian women's preferences for birth attendant and birth place. Birth, 2005, 32:20-6.

47. Kabakian-Khasholian $\mathrm{T}$ et al. Women's experiences of maternity care: satisfaction or passivity? Social science and medicine, 2000, 51:103-13.
48. Appropriate technology for birth. Lancet, 1985, 2:436-7.

49. Tatar et al. Women's perceptions of caesarean section: reflections from a Turkish teaching hospital. Social science and medicine, 2000, 50:1227-33.

\section{UM-ESCWA launches a supportive guide in the Arab region on gen- der in the millennium development goals}

Beirut, 14 September 2008 On the occasion of the 12th Regional Coordination Mechanism Meeting (RCM), UM-ESCWA Executive Secretary, Bader Omar AIDafa, launched a report on Gender in the Millennium Development Goals: Information guide for Arab Millennium Development Goals reports at the UY House, Beirut in the presence of representatives of UM regional organizations and media institutions.

The Guide is the result of cooperation among the various UM organizations as a response to the need to develop a single information gathering monitoring system for gender sensitive indicators and sex-disaggregated data. It summarizes the main gender issues and concerns in the region in the context of each millennium goal. It also provides a detailed assessment of the availability of sex-disaggregated data and gender sensitive indicators in the Arab region for gender responsive monitoring and reporting of MDGs. The full report can be accessed at: http://www.escwa.un.org/divisions/scu/GenderMDG/ index.asp 